\section{1}

2

3

\title{
In-situ sequestration of hydraulic fracturing fluid in Longmaxi shale gas formation in Sichuan Basin
}

\section{Supporting Information}

\section{Table of contents}

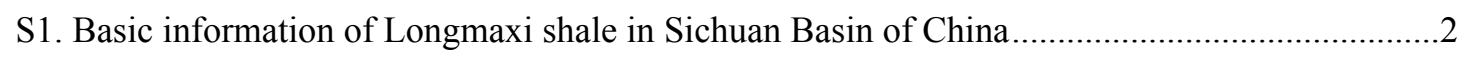

Geological information of Longmaxi shale gas plays...........................................................

Flowback wastewater information of Longmaxi shale gas wells ............................................2

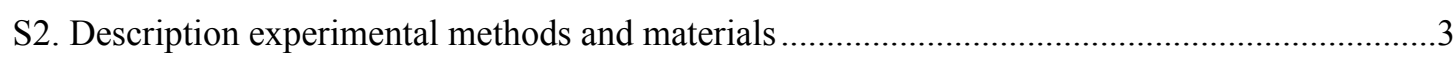

Field emission scanning electron microscopy (SEM) analysis of shale nanopores....................3

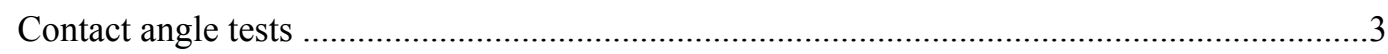

Nuclear magnetic resonance (NMR) tests........................................................................

Core flooding experiments with flowback fluid ……….....................................................

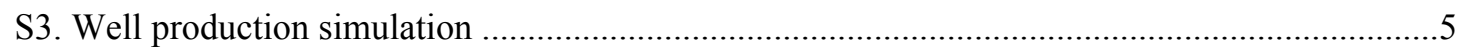

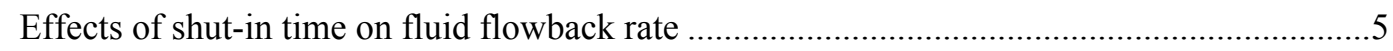

The damage of fracturing fluid residues to well productivities. ..............................................6

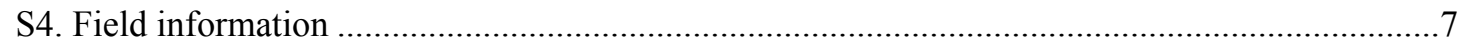

Fractured well information in shut-in operation anaylsis ....................................................

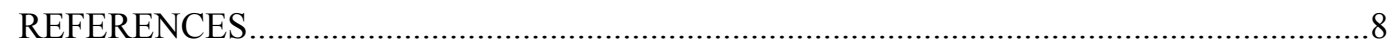




\section{S1. Basic information of Longmaxi shale in Sichuan Basin of China}

\section{Geological information of Longmaxi shale gas plays}

In this paper, our experimental shale samples, fracturing flowback fluid and well production data come from the Longmaxi shale gas wells of Sichuan Basin in China. Currently, Fuling, Changning and Weiyuan shale district are the three commercial shale gas plays in Sichuan Basin. The Longmaxi shale formation has wide and stable sediments in southeast Sichuan Basin, with a thickness of $100 \sim 120 \mathrm{~m}$, in which the bottom layers (about 30m) presents the highest gas content and production potential and is regarded as the target zone of geological exploration. ${ }^{1}$ The typical formation parameters of the main longmaxi shale gas plays are shown in Table S1.

Table S1. Basic information of the four commercial shale gas plays in Sichuan Basin of China.

\begin{tabular}{cccccccccc}
\hline \multirow{2}{*}{ Area } & \multirow{2}{*}{$\begin{array}{c}\text { Depth } \\
(\mathrm{m})\end{array}$} & $\begin{array}{c}\text { Pressure } \\
\text { coefficient }\end{array}$ & $\begin{array}{c}S_{\mathrm{wi}} \\
(\%)\end{array}$ & \multicolumn{6}{c}{ Mineral components of whole rock (wt.\%) } \\
\cline { 6 - 10 } & & & Quartz & Feldspar & Calcite & Dolomite & Pyrite & Clay minerals \\
\hline Fuling & $2100-3500$ & $1.35 \sim 1.55$ & $10 \sim 29$ & 51.5 & 3.0 & 2.4 & 2.8 & 2.4 & 37.9 \\
Changning & $2000-4500$ & $1.25 \sim 2.0$ & $20 \sim 40$ & 45.3 & 11.0 & 6.8 & 2.1 & 3.7 & 31.1 \\
Weiyuan & $2000-3700$ & $1.1 \sim 1.5$ & $35 \sim 46$ & 32.9 & 32.5 & 3.6 & 5.3 & 2.4 & 23.3 \\
Pengshui & $2200-2600$ & $1.02 \sim 1.05$ & $45 \sim 65$ & 36.6 & 19.1 & 7.1 & 4.3 & 2.9 & 30.0 \\
\hline
\end{tabular}

${ }^{a}$ The depth and reservoir gas pressure coefficient of three shale plays (Fuling, Changning, Weiyuan) are cited from Dong et al. (2014) ${ }^{2}$. $S_{\text {wi }}$-initial water saturation of Longmaxi shales; I-illite, K-kaolinite, C-chlorite, I/S-illite/smectite.

\section{Flowback wastewater information of Longmaxi shale gas wells}

Multistage fracturing is a common strategy to stimulate shale gas formation, typically with huge volume and high pressure fracturing fluid injected into shale to generate complex fracture networks. However, the recovered fluid presents a high risk of environmental contamination due to high salinity brine (varied dissolved salts), radioactivity, organic residues and mineral particles. Table S2 and Table S3 display some information about the inorganic constituents of the flowback wastewater in Longmaxi shale formation and the comparison with shale plays in other countries. ${ }^{3-6}$ Figure S1 shows the field images of the flowback fluid at different production time.

Table S2. Typical TDS and flowback rates of HF fluid for shale formation in China and North America.

\begin{tabular}{|c|c|c|c|}
\hline Producing Area & TDS (mg/L) & Flowback rate $(\%)$ & Source \\
\hline Weiyuan (China) & $15000-35000$ & $20-40$ & \multirow{4}{*}{$\begin{array}{c}\text { These data come from the shale } \\
\text { gas well statistics of oil gas and } \\
\text { companies in Sichuan Basin }\end{array}$} \\
\hline Changning (China) & $20000-60000$ & $10-35$ & \\
\hline Fuling (China) & $13000-30000$ & $<10$ & \\
\hline Pengshui (China) & $15000-55000$ & $40-60$ & \\
\hline Fayetteville & 25000 & $15-30$ & Osborn et al., $2012^{7}$; \\
\hline Barnett & 60000 & up to 100 & Wattenbarger and Alkouh, $2013^{8}$ \\
\hline Haynesville & $110000-120000$ & $<20$ & Zou et al., $2018^{1}$ \\
\hline Marcellus & $100000-180000$ & $9-35$ & Boschee,20145; Vengosh et al., \\
\hline Bakken & $150000-300000$ & $15-40$ & 2014; Warner et al., 2013a, \\
\hline Eagle Ford & $15000-55000$ & $<15$ & 2013b $\mathrm{b}^{10,11}$; Haluszczak et al., \\
\hline Permian Basin & $20000-300000$ & $20-40$ & $2013^{12}$; He et al., 2016 ${ }^{13}$; Nguyen \\
\hline Denver-Julesburg & $20000-65000$ & $15-30$ & et al., $2018^{14}$ \\
\hline
\end{tabular}


Table S3. Comparison of ion composition of the flowback fluid among different shale plays.

\begin{tabular}{|c|c|c|c|c|c|c|c|c|}
\hline Constituents & Fuling & Pengshui & Changning & Weiyuan & Marcellus $^{4}$ & Polish $^{3}$ & $\begin{array}{c}\text { Denver } \\
\text { Julesburg }\end{array}$ & $\begin{array}{c}\text { Criteria for surface } \\
\text { water quality in China }\end{array}$ \\
\hline $\mathrm{pH}$ & 7.46 & 6.84 & 7.48 & 7.21 & 6.56 & 5.79 & 6.80 & $6.5-8.5$ \\
\hline $\mathrm{Na}^{+}(\mathrm{mg} / \mathrm{L})$ & 8296 & 15100 & 19830 & 8740 & 24123 & 24590 & 6944 & 200 \\
\hline $\mathrm{K}^{+}(\mathrm{mg} / \mathrm{L})$ & 157 & 231 & 768 & 243 & - & 515 & - & - \\
\hline $\mathrm{NH}_{4}^{+}(\mathrm{mg} / \mathrm{L})$ & 23 & 37 & - & - & - & 134 & 25 & - \\
\hline $\mathrm{Ca}^{2+}(\mathrm{mg} / \mathrm{L})$ & 564 & 768 & 3870 & 962 & 7220 & 6520 & 524 & - \\
\hline $\mathrm{Mg}^{2+}(\mathrm{mg} / \mathrm{L})$ & 131 & 105 & 274 & 336 & 632 & 865 & 106 & - \\
\hline $\mathrm{Fe}^{2+/ 3+}(\mathrm{mg} / \mathrm{L})$ & 7 & 29 & 62 & 55 & 112 & 20 & 81 & 0.3 \\
\hline $\mathrm{Al}^{3+}(\mathrm{mg} / \mathrm{L})$ & 3 & - & 8 & 6 & - & - & - & 0.2 \\
\hline $\mathrm{Ba}^{2+}(\mathrm{mg} / \mathrm{L})$ & 259 & 412 & 341 & 138 & 2224 & 226 & 9 & 1 \\
\hline $\mathrm{Sr}^{2+}(\mathrm{mg} / \mathrm{L})$ & 155 & 304 & 320 & 67 & 1695 & 1110 & 60 & - \\
\hline $\mathrm{Cl}^{-}(\mathrm{mg} / \mathrm{L})$ & 18652 & 36470 & 29700 & 13110 & 57447 & 66400 & 13600 & 250 \\
\hline $\mathrm{Br}^{-}(\mathrm{mg} / \mathrm{L})$ & 233 & 470 & 228 & 180 & 511 & 670 & 87 & - \\
\hline $\mathrm{SO}_{4}^{2-}(\mathrm{mg} / \mathrm{L})$ & 105 & 41 & 172 & 94 & 71 & - & 1 & 250 \\
\hline $\mathrm{HCO}_{3}{ }^{-}(\mathrm{mg} / \mathrm{L})$ & 1263 & 310 & 660 & 451 & 165 & 976 & - & - \\
\hline Total (mg/L) & 29848 & 54284 & 56233 & 24382 & 94986 & 102026 & 21437 & 1000 \\
\hline $\mathrm{Ra}(\mathrm{pCi} / \mathrm{L})$ & - & - & 327 & 225 & 743 & 216 & - & - \\
\hline $\mathrm{U}(\mathrm{pCi} / \mathrm{L})$ & - & - & 185 & 58 & 43 & 1182 & - & - \\
\hline
\end{tabular}
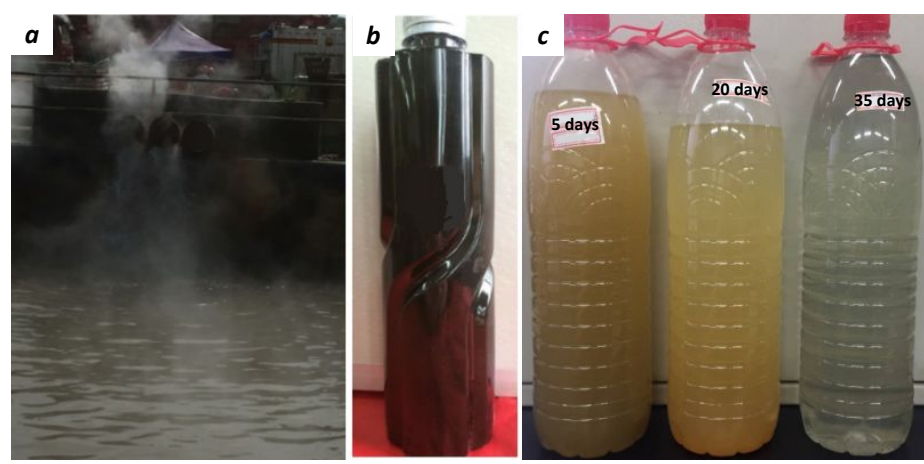

Figure S1. The flowback hydraulic fracturing fluid of shale gas wells in Sichuan Basin of China: (a) the storage pond of flowback wastewater; (b) the flowback fluid in the first several hours after well production, and the fluid may include fracturing fluid, residue drilling fluid, other working fluids and particles from shale and cementing concrete, so it presents a black color; (c) the flowback fluid after producing 5, 20 and 35 days, and the color changes indicated that the total solid and TOC content decreased with the increasing of production time.

\section{S2. Description experimental methods and materials}

\section{Field emission scanning electron microscopy (SEM) analysis of shale nanopores}

In order to get high definition images of the shale nanopores, Field emission scanning electron microscopy was used to observe the shale samples (Longmaxi shale formation). In this tests, shale should first be cut into small chips, with a size of $10 \mathrm{~mm} \times 10 \mathrm{~mm} \times 2 \sim 3 \mathrm{~mm}$. As the shale surface is too rough to observe the nanopores, focused ion beam (Argon ion) was used to polish the sample surface with HITACHI IM4000 instrument. Then the samples was observed by FEI Quanta250 FEG, and we got the FE-SEM images of shale nanopores, as shown in Figure 3 in the manuscript.

\section{Contact angle tests}

In contact angles measurements, the shale samples (Longmaxi shale formation) were small plugs with a diameter of 
$2.54 \mathrm{~cm}$ and a height of $1 \mathrm{~cm}$. In order to ensure smooth of the surfaces, 180 and 1000 mesh abrasive papers were used to polish the end faces of the plugs. Then samples was successively put into alcohol and distilled water, and ultrasonic cleaning was used to remove the surface impurities. After drying at $60^{\circ} \mathrm{C}$ for $48 \mathrm{~h}$, Kruss-100 Drop Shape Analyzer were used to measure the contact angles between the samples and the distilled water as well as flowback fluid (20 days after well production, after filtration).

\section{Nuclear magnetic resonance (NMR) tests}

In this experiment, the shale plugs have a size of $2.51 \mathrm{~cm}$ (in diameter) $\times 2.354 \sim 2.465 \mathrm{~mm}$ (in length), and after drying for about $48 \mathrm{~h}$, the sample mass and porosity were measured. Before the test, shale samples were vacuumized for $4 \mathrm{~h}$. Then the samples were saturated with water to a $100 \%$ saturation condition. Using the fully saturated samples, the initial NMR curves were first tested with MiniMR-60 NMR analysis tester (manufactured by NIUMAG of Shanghai) to get the $T_{2}$ spectrum. Then a two hours centrifugation under a pressure of 200 psi was conducted for the fully saturated samples to drive out some mobile water. Immediately after the centrifugation, the NMR curves were tested again. Putting the NMR curves before and after centrifugation together, we can figure out in which part of pores the water can be remove out and the effects of shale nanopores in sequestering the imbibed water, as shown in Figure 6 in the manuscript.

\section{Core flooding experiments with flowback fluid}

In the core flooding experiments, all the shale samples were taken from the Longmaxi shale formation, and the basic information of the samples were displayed in Table S4. The displacing fluid was the flowback fracturing fluid (20 days and 35 days) of Changning Longmaxi shale gas wells in Sichuan Basin, which has an initial turbidity of 97 and 51 NTU, respectively. The purpose of this experiment was to analyze the organic solids sorption and retention in shale microfractures during the HF flowback process and its influence on fracture permeability.

The experimental apparatus of the core flooding experiments were shown in Figure S2, and the experimental procedures were as follows:

- Artificial shale plugs were selected and dried at $60^{\circ} \mathrm{C}$ till the mass of the samples keeping unchanged.

- Put the shale plug into the core holder and a confining pressure of $3 \mathrm{MPa}$ was exerted. After an aging of $24 \mathrm{~h}$ (to reduce the stress sensitivity of the shale fractures), the gas permeability of the samples were tested first ${ }^{15}$. In this process, valves 1 and 3 were closed and valves 2 and 4 were opened (Figure S2). Pure nitrogen was used to test the sample gas permeability at different inlet pressure, with a constant outlet pressure of one atm.

- After the gas permeability measurement, valves 2 and 4 were closed and valves 1 and 3 were opened. The testing fluid (the flowback HF fluid from shale gas wells) was pumped into the shale plugs with an increasing driving pressure. At the same time, the fluid at the outlet was collected and the fluid turbidity was measured with a turbidimeter (2100Q, HACH Instrument) at various time-points. This process may last about $24 \mathrm{~h}$.

- Then the gas permeability of the samples was tested again (valves 1 and 3 were closed and valves 2 and 4 were 

opened), so as to evaluate the fracture permeability damages caused by the flowback fluid.

- When all the testing procedures were completed, the shale plugs were taken out, and images of the fracture surfaces were taken to analyze the organic solids adsorption and retention.

Table S4. Basic information of shale samples in core flooding experiments

\begin{tabular}{ccccc}
\hline Samples & $\begin{array}{c}\text { Length } \\
(\mathrm{cm})\end{array}$ & $\begin{array}{c}\text { Diameter } \\
(\mathrm{cm})\end{array}$ & \multicolumn{2}{c}{$\begin{array}{c}\text { Dry mass } \\
(\mathrm{g})\end{array}$} \\
\hline $\mathrm{CN}-4$ & 3.450 & 2.47 & 39.885 & single artificial fracture \\
CN-5 & 3.148 & 2.51 & 37.599 & single artificial fracture \\
\hline
\end{tabular}

101

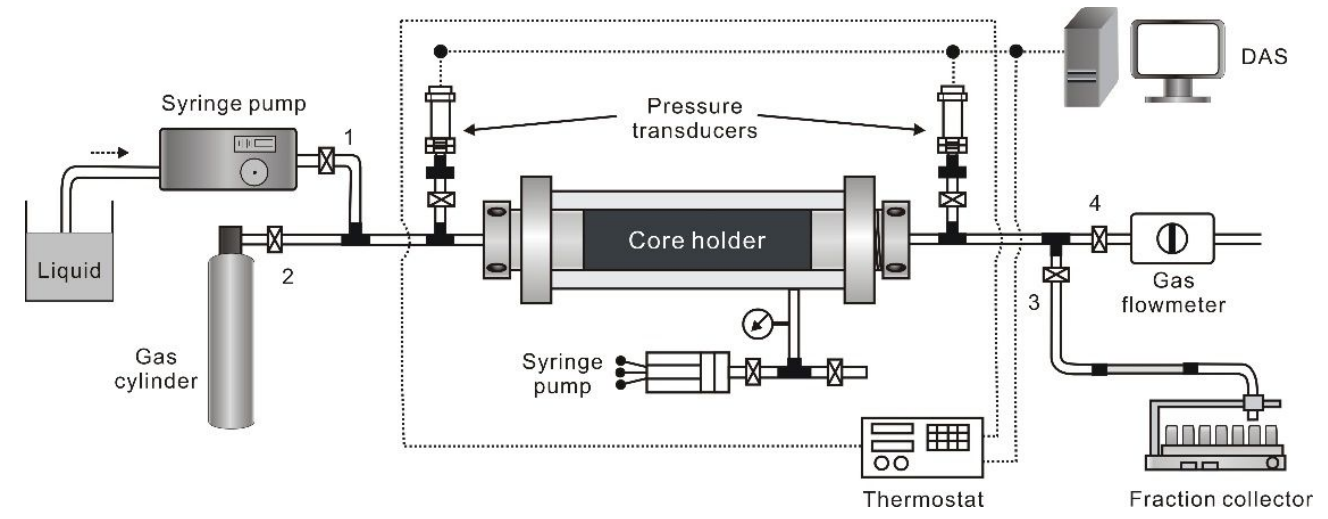

Figure S2. Experimental apparatus core flooding experiments.

\section{S3. Well production simulation}

\section{Effects of shut-in time on fluid flowback rate}

As shown in Table S5, many simulation researches consistently demonstrate that with the growing of shut-in time, the flowback rates of shale gas wells decrease remarkably in spite of the differences of the simulation models, input parameters and results ${ }^{16-24}$.

Table S5. Simulation results about the relations of shut-in time and HF fluid flowback rate in shale gas wells

\begin{tabular}{|c|c|c|c|c|}
\hline NO. & Shut-in time & $\begin{array}{c}\text { Flowback rates or recovered volume } \\
\text { of water }\end{array}$ & $\begin{array}{l}\text { Production time } \\
\text { after shut-in }\end{array}$ & Literature \\
\hline 1 & $0,1,10,30$ days & $31.7 \%, 30.1 \%, 25.3 \%, 21.4 \%$ & 1 & Crafton and Gunderson, $2007^{17}$ \\
\hline 2 & $0,1,10,30,90$ days & $29.5 \%, 26.8 \%, 18.9 \%, 11.6,2.9 \%$ & 150 days & Jurus et al., $2013^{20}$ \\
\hline 3 & $0,10,20,30$ days & $49.1 \%, 44.6 \%, 42.0 \%, 40.8 \%$ & 5 years & Liu et al., $2015^{22}$ \\
\hline 4 & $0,30,90$ days & $43.2 \%, 36.3 \%, 32.2 \%$ & 1000 days & Almulhim et al., $2014^{16}$ \\
\hline 5 & $0,7,15,30$ days & $44.9 \%, 34.4 \%, 26.1 \%, 17.4 \%$ & 500 days & Fakcharoenphol et al., $2016^{18}$ \\
\hline 6 & $0,1,7,30$ days & $12.8 \%, 12.2 \%, 9.5 \%, 4.5 \%$ & 100 days & Seales et al., $2017^{21}$ \\
\hline 7 & $0,5,10,30,100$ days & $25.4 \%, 20.5 \%, 18.6 \%, 15.1 \%, 11.2 \%$ & 3 years & Zhang et al., $2017^{23}$ \\
\hline 8 & $5,10,25,70$ days & $26500,20300,17560,10110 \mathrm{bbl}$ & 90 days & Bertoncello et al., $2014^{24}$ \\
\hline 9 & $50,100,150$ days & $679,569,487 \mathrm{bbl}$ & 30 days & Ghanbari and Dehghanpour, $2016^{19}$ \\
\hline
\end{tabular}


Table S6. Parameter values of a well production model to evaluate the hydraulic and natural damages on well production rate (A: no damages; $\mathrm{B}$ : only consider the permeability damage caused by fracturing residues in hydraulic fractures; $\mathrm{C}$ : only consider the permeability damage caused by fracturing residues in natural fractures)

\begin{tabular}{|c|c|c|c|}
\hline Parameters & $\mathbf{A}$ & B & $\mathbf{C}$ \\
\hline Grid block $(x, y, z)$ & $(165,165,1)$ & $(165,165,1)$ & $(165,165,1)$ \\
\hline Length of unit block (m) & $(3.85,3.85,15.4)$ & $(3.85,3.85,15.4)$ & $(3.85,3.85,15.4)$ \\
\hline Space between natural fractures $(\mathrm{m})$ & $(1.52,1.52,3.05)$ & $(1.52,1.52,3.05)$ & $(1.52,1.52,3.05)$ \\
\hline Organic porosity (fraction) & 0.15 & 0.15 & 0.15 \\
\hline Inorganic porosity (fraction) & 0.03 & 0.03 & 0.03 \\
\hline Organic/inorganic volume ratio (fraction) & $(0.15: 0.85)$ & $(0.15: 0.85)$ & $(0.15: 0.85)$ \\
\hline Organic density $\left(\mathrm{g} / \mathrm{cm}^{3}\right)$ & 1.61 & 1.61 & 1.61 \\
\hline Organic matrix permeability $(\mathrm{mD})$ & 0.008 & 0.008 & 0.008 \\
\hline Inorganic matrix permeability $(\mathrm{mD})$ & 0.03 & 0.03 & 0.03 \\
\hline Natural fracture permeability $(\mathrm{mD})$ & $(2,2,1)$ & $(2,2,1)$ & $(1.8,1.8,0.9)$ \\
\hline Hydraulic fracture permeability (D) & $(5,5,2)$ & $(4.5,4.5,1.8)$ & $(5,5,2)$ \\
\hline Matrix compressibility (1/MPa) & $1.5 \times 10^{-7}$ & $1.5 \times 10^{-7}$ & $1.5 \times 10^{-7}$ \\
\hline Nature fracture compressibility (1/MPa) & $3 \times 10^{-4}$ & $3 \times 10^{-4}$ & $3 \times 10^{-4}$ \\
\hline Hydraulic fracture compressibility (1/MPa) & $3 \times 10^{-5}$ & $3 \times 10^{-5}$ & $3 \times 10^{-5}$ \\
\hline Biot coefficient (Dimensionless) & 1.0 & 1.0 & 1.0 \\
\hline Poisson's ratio (fraction) & 0.25 & 0.25 & 0.25 \\
\hline Langmuir volume $\left(\mathrm{cm}^{3} / \mathrm{g}\right)$ & 1.9 & 1.9 & 1.9 \\
\hline Langmuir pressure $(\mathrm{MPa})$ & 12 & 12 & 12 \\
\hline Production time $(\mathrm{d})$ & 365 & 365 & 365 \\
\hline
\end{tabular}

In this paper, the authors adopted a specific shale gas producing model to simulate the effects of fracturing fluid residue on damage on well production. This model couples embedded discrete fractures, multiple interacting continua, and geomechanics to accurately simulate the fluid flow in shale gas reservoirs with multiscale fractures, and more detailed one can refer to our another published article ${ }^{25}$.

In this simulation work, we considered three different situations: in Group A: there is no damages caused by the fracturing fluid residues; in Group B: only consider a 10\% permeability reduction of the hydraulic fractures which induced by the residue adsorption in fracture surfaces and blocking in proppant pack; in Group C: only consider a $10 \%$ permeability reduction of the natural fractures which induced by the residue retention during long term shut-in operations. The values of each parameters were displayed in Table S6. The results showed that at the same permeability damage rate, the residues retention occurring in primary propped hydraulic fractures has a relatively bigger damage rate to well productivity than that occurring in natural fractures (Figure S3), and it indicates the sequestration more fluid in shale gas formation would bring additional harms to well production. 


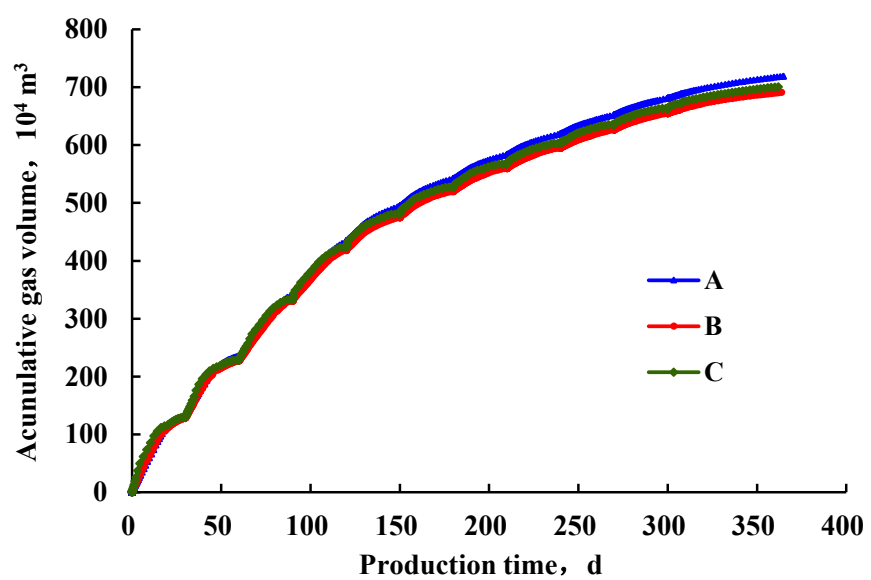

Figure S3. Well accumulative production curves versus time (A: no damages; B: only consider the permeability damage in hydraulic fractures; $\mathrm{C}$ : only consider the permeability damage in natural fractures)

\section{S4. Field information}

\section{Fractured well information in shut-in operation anaylsis}

Six wells in Longmaxi shale formation were chosen to analyze the influence of shut-in time on fluid flowback rate, and these wells were divided into two groups. As shown in Table S7, the four wells titled 'CW' are located in the same platform of Changning Longmaxi shale formation, and the two wells titled 'WW' come from one platform in Weiyuan Longmaxi shale formation. Wells from the same platform have very similar geological conditions, horizontal section length, fracturing stages, water and propant consumption of these wells, so their comparison would be more convincing when illustrating the effects of shut-in time on HF fluid flowback rate.

Table S7. Basic stimulation information of the selected six shale gas wells in Longmaxi shale formation

\begin{tabular}{cccccc}
\hline Wells & $\begin{array}{c}\text { Length of horizontal } \\
\text { section }(\mathrm{m})\end{array}$ & $\begin{array}{c}\text { Fracturing stages } \\
\text { (Dimensionless) }\end{array}$ & $\begin{array}{c}\text { Time of well } \\
\text { stimulation }(\mathrm{d})\end{array}$ & $\begin{array}{c}\text { Injected HF fluid } \\
\text { volume }\left(\mathrm{m}^{3}\right)\end{array}$ & $\begin{array}{c}\text { Well shut-in time } \\
(\mathrm{d})\end{array}$ \\
\hline CW-1 & 1780 & 24 & 45 & 46727 & 5 \\
CW-2 & 1760 & 24 & 50 & 46002 & 20 \\
CW-3 & 1925 & 27 & 50 & 51742 & 15 \\
CW-4 & 1500 & 22 & 43 & 44892 & 18 \\
WW-1 & 1380 & 14 & 38 & 37841 & 36 \\
WW-2 & 1500 & 15 & 45 & 38629 & 31 \\
\hline
\end{tabular}
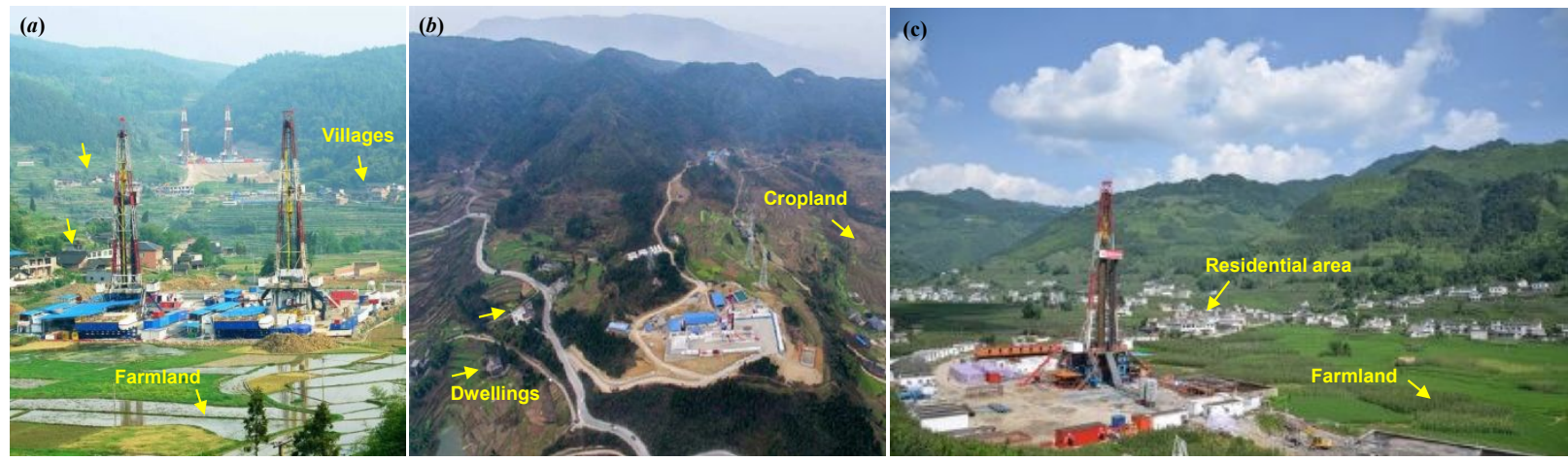

Figure S4. The geomorphology characters and surrounding circumstances of Longmaxi shale gas well sites in Sichuan Basin. The online resources of image (a), (b) and (c) are http://www.cnenergy.org/yq/trq/201710/t20171016 447149.html, http://www.360doc.com/content/17/1222/09/40430494_715282085.shtml,and 
149 (1) Zou, C.; Ni, Y.; Li, J.; Kondash, A.; Coyte, R.; Lauer, N.; Cui, H.; Liao, F.; Vengosh, A., The water footprint of hydraulic fracturing

150 in Sichuan Basin, China. Sci. Total Environ. 2018, 630, 349-356.

151 (2) Dong D.; Shi Z.; Guan Q. Progress, challenges and prospects of shale gas exploration in the Wufeng-Longmaxi reservoirs in the 152 Sichuan Basin. Natural Gas Industry 2018, 38(4), 67-76.

153 (3) Abramowska, A.; Gajda, D. K.; Kiegiel, K.; Miśkiewicz, A.; Drzewicz, P.; Zakrzewska-Kołtuniewicz, G., Purification of flowback 154 fluids after hydraulic fracturing of Polish gas shales by hybrid methods. Sep. Sci. Technol. 2018, 53 (8), $1207-1217$.

155 (4) Barbot, E.; Vidic, N. S.; Gregory, K. B.; Vidic, R. D., Spatial and temporal correlation of water quality parameters of produced waters 156 from Devonian-age shale following hydraulic fracturing. Environ. Sci. Technol. 2013, 47 (6), 2562-2569.

157 (5) Boschee, P., Produced and flowback water recycling and reuse: economics, limitations, and technology. Oil and Gas Facilities 2014, $1583(1), 16-21$.

159 (6) Kong, F.-x.; Chen, J.-f.; Wang, H.-m.; Liu, X.-n.; Wang, X.-m.; Wen, X.; Chen, C.-m.; Xie, Y. F., Application of coagulation-UF 160 hybrid process for shale gas fracturing flowback water recycling: Performance and fouling analysis. J. Membr. Sci. 2017, 524, 460161469.

162 (7) Osborn, S. G.; McIntosh, J. C.; Hanor, J. S.; Biddulph, D., Iodine-129, 87Sr/86Sr, and trace elemental geochemistry of northern 163 Appalachian Basin brines: Evidence for basinal-scale fluid migration and clay mineral diagenesis. American Journal of Science 2012, $164312(3), 263-287$.

165 (8) Wattenbarger, R. A.; Alkouh, A. B. In New advances in shale reservoir analysis using flowback data, SPE eastern regional meeting, 1662013.

167 (9) Vengosh, A.; Jackson, R. B.; Warner, N.; Darrah, T. H.; Kondash, A., A critical review of the risks to water resources from 168 unconventional shale gas development and hydraulic fracturing in the United States. Environ. Sci. Technol. 2014, 48 (15), 8334-8348.

169 (10) Warner, N. R.; Christie, C. A.; Jackson, R. B.; Vengosh, A., Impacts of shale gas wastewater disposal on water quality in western 170 Pennsylvania. Environ. Sci. Technol. 2013, 47 (20), 11849-11857.

171 (11) Warner, N. R.; Kresse, T. M.; Hays, P. D.; Down, A.; Karr, J. D.; Jackson, R. B.; Vengosh, A., Geochemical and isotopic variations 172 in shallow groundwater in areas of the Fayetteville Shale development, north-central Arkansas. Appl. Geochem. 2013, 35, 207-220.

173 (12) Haluszczak, L. O.; Rose, A. W.; Kump, L. R., Geochemical evaluation of flowback brine from Marcellus gas wells in Pennsylvania, 174 USA. Appl. Geochem. 2013, 28, 55-61.

175 (13) He, C.; Vidic, R. D., Application of microfiltration for the treatment of Marcellus Shale flowback water: Influence of floc breakage 176 on membrane fouling. J. Membr. Sci. 2016, 510, 348-354.

177 (14) Nguyen, T.; Romero, B.; Vinson, E.; Wiggins, H., Effect of salt on the performance of drag reducers in slickwater fracturing fluids. $J$. 178 Pet. Sci. Eng. 2018, 163, 590-599.

179 (15) Cui, X.; Bustin, A.; Bustin, R. M., Measurements of gas permeability and diffusivity of tight reservoir rocks: different approaches and 180 their applications. Geofluids 2009, 9 (3), 208-223.

181 (16) Almulhim, A.; Alharthy, N.; Tutuncu, A. N.; Kazemi, H. In Impact of imbibition mechanism on flowback behavior: A numerical 182 study, SPE Abu Dhabi International Petroleum Exhibition and Conference, 2014.

183 (17) Crafton, J. W.; Gunderson, D. W. In Stimulation Flowback Management--Keeping a Good Completion Good, SPE Annual Technical 184 Conference and Exhibition, 2007.

185 (18) Fakcharoenphol, P.; Torcuk, M.; Kazemi, H.; Wu, Y.-S., Effect of shut-in time on gas flow rate in hydraulic fractured shale reservoirs. 186 J. Nat. Gas Sci. Eng. 2016, 32, 109-121.

187 (19) Ghanbari, E.; Dehghanpour, H., The fate of fracturing water: A field and simulation study. Fuel 2016, 163, $282-294$.

188 (20) Jurus, W. J.; Whitson, C. H.; Golan, M. In Modeling water flow in hydraulically-fractured shale wells, SPE Annual Technical 189 Conference and Exhibition, 2013.

190 (21) Seales, M. B.; Dilmore, R.; Ertekin, T.; Wang, J. Y., A Numerical Study of Factors Affecting Fracture-Fluid Cleanup and Produced 191 Gas/Water in Marcellus Shale: Part II. SPE Journal 2017, 22 (2), 596-614.

192 (22) Liu N.; Liu M.; Zhang S., Flowback patterns of fractured shale gas wells. Natural Gas Industry 2015, 35(3), 50-54.

193 (23) Zhang T.; Li X.; Yang L.; Li J., Effects of shut-in timing on flowback rate and productivity of shale gas wells. Natural Gas Industry $1942017,37(8), 48-60$.

195 (24) Bertoncello, A.; Wallace, J.; Blyton, C.; Honarpour, M.; Kabir, C. In Imbibition and water blockage in unconventional reservoirs: well 196 management implications during flowback and early production, SPE/EAGE European Unconventional Resources Conference and 197 Exhibition, 2014.

198 (25) Wang, K.; Liu, H.; Luo, J.; Wu, K.; Chen, Z., A Comprehensive Model Coupling Embedded Discrete Fractures, Multiple Interacting 199 Continua, and Geomechanics in Shale Gas Reservoirs with Multiscale Fractures. Energy \& Fuels 2017, 31 (8), 7758-7776. 